\title{
A Violência Escolar no Contexto de Privação de Liberdade
}

School Violence in the Context of Deprivation of Freedom

la Violencia Escolar en el Contexto de Privación de Libertad

Joelma Oliveira da Silva

Faculdade de Tecnologia e Ciências de Feira de Santana

Marilena Ristum

Universidade Federal da Bahia

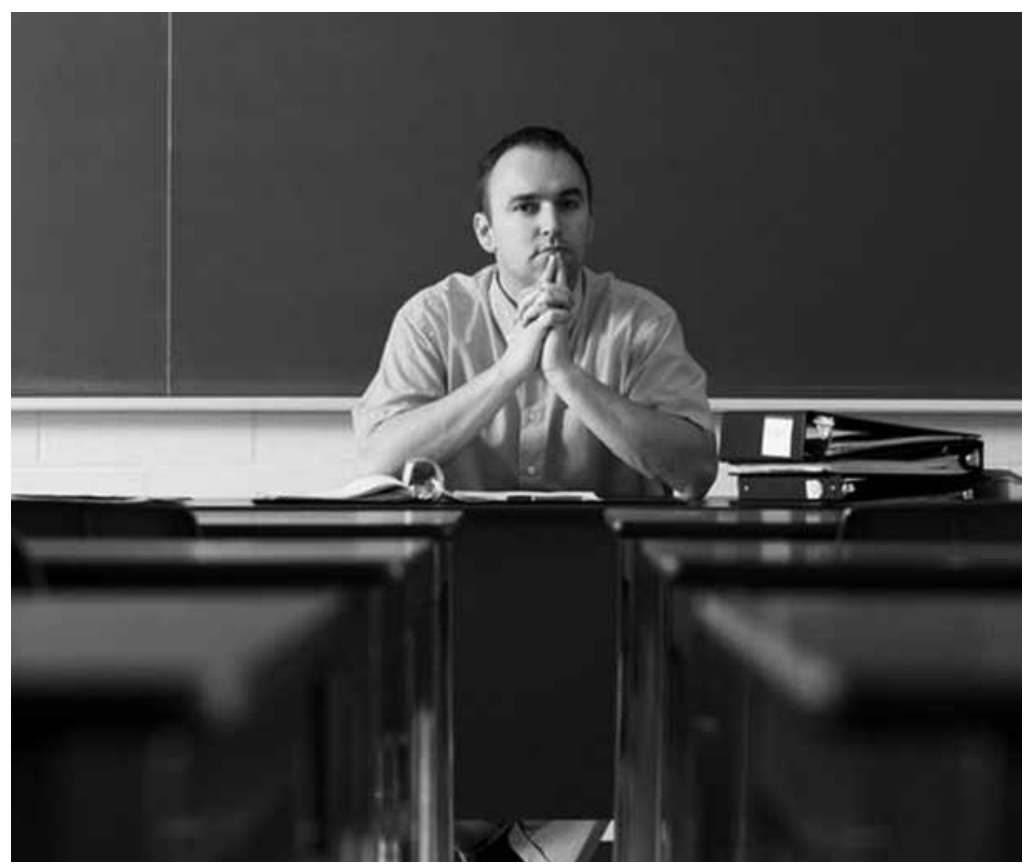


Resumo: A violência no contexto escolar é um fenômeno que apresenta um forte incremento, atraindo crescentemente a atenção dos pesquisadores da área. Entretanto, as escolas instaladas nas unidades de privação de liberdade não têm merecido o mesmo interesse, apesar de sua reconhecida importância no direcionamento dos seus alunos, especialmente quando são adolescentes, para formas não delituosas de viver. Este artigo focaliza a violência dirigida ao professor por seus alunos adolescentes, em sala de aula, no contexto de unidades de privação de liberdade. A pesquisa objetivou compreender a percepção dos professores acerca do fenômeno, discutindo as especificidades das relações de ensino-aprendizagem, marcadas pelas características de uma escola inserida no sistema socioeducativo. Para a obtenção dos dados, foi utilizado um questionário com questões estruturadas e semiestruturadas, que permitiu constatar que, para os professores, as manifestações de violência se dão, em grande parte, de formas sutis, e são percebidas como capazes de afetar diretamente a atuação dos mesmos em sala de aula. Palavras-chave: Violência escolar. Interação professor-aluno. Privação de liberdade. Adolescentes.

Abstract: Violence in the school context is a phenomenon that has been strongly incremented and has also attracted the attention of researchers in the field. However, schools located in units of deprivation of freedom haven 't aroused the same interest, in spite of their already acknowledged importance in directing the students, specially teenagers, into non-transsgressive ways of living. This article focuses the violence directed to the teacher from his teenage students in the classroom, in the context of deprivation of freedom units. The research aimed at understanding the teachers' perceptions on the phenomenon, discussing teaching-learning relationships marked by the characteristics of a school inside the prision system. To obtain the data, a questionnaire with structured and semi-structured questions was used, allowing us to find that, for the teachers, violence manifestations are mostly shown in a subtle manner and perceived as capable of directly affect their performance in the classroom.

Keywords: School violence. Teacher student interaction. Deprivation of freedom. Adolescents.

Resumen: La violencia en el contexto escolar es un fenómeno que presenta un fuerte incremento, atrayendo crecientemente la atención de los investigadores del área. No obstante, las escuelas instaladas en las unidades de privación de libertad no han merecido el mismo interés, a pesar de su reconocida importancia en el direccionamiento de sus alumnos, especialmente cuando son adolescentes, para formas no delictuosas de vivir. Este artículo focaliza la violencia dirigida al profesor por sus alumnos adolescentes, en sala de aula, en el contexto de unidades de privación de libertad. La pesquisa tuvo por objetivo comprender la percepción de los profesores acerca del fenómeno, discutiendo las especificidades de las relaciones de enseñanzaaprendizaje, marcadas por las características de una escuela inserida en el sistema socioeducativo. Para la obtención de los datos, fue utilizado un cuestionario con cuestiones estructuradas y semi-estructuradas, que permitió constatar que, para los profesores, las manifestaciones de violencia se dan, en gran parte, de formas sutiles, y son percibidas como capaces de afectar directamente la actuación de los mismos en sala de aula. Palabras clave: Violencia escolar. Interacción profesor-estudiante. Privación de libertad. Adolescente.

A violência, considerada um fenômeno crescente que incide, de forma direta e indireta, nos distintos domínios da convivência social, tem sido um tema constante no cenário dos debates acerca dos fenômenos sociais. De acordo com Minayo (1994), "a violência é um dos eternos problemas da teoria social e da prática política e relacional da humanidade" (p. 2), pois está presente em todas as sociedades. A própria história da humanidade mostra-se atravessada por episódios marcados por atos de violência nas diferentes formas e épocas, utilizando-se, muitas vezes, um discurso ideológico justificador de tais atos.
Apesar da constância nas discussões sociais e políticas e da presença do fenômeno nas diferentes épocas e sociedades, alguns autores enfatizam a dificuldade de definição da violência, dificuldade que se deve, principalmente, à complexidade que configura a temática. Ristum e Bastos (2004) abordam essa complexidade através de quatro aspectos: a polissemia do conceito e os problemas da definição de violência a violência é apresentada na literatura de diferentes formas, sob diversas classificações e rotulações; a controvérsia na delimitação do objeto da violência - que pode assumir diferentes formas e graus, variando de acordo 
com as normas socioculturais e legais, a quantidade, a variedade e a interação de suas causas - um fenômeno multideterminado, sendo que os diversos fatores se apresentam em interação, e, finalmente, a falta de consenso sobre a natureza da violência - a literatura apresenta concepções diferentes acerca desse tema, tendendo, de modo geral, ou para posições inatistas ou para posições que defendem a gênese social da violência.

Assim como em todos os fenômenos psicossociais sobre os quais a Academia tem se debruçado, as tentativas de compreensão, no campo da violência, fundamentam-se nas concepções de homem adotadas pelos pesquisadores e nos pressupostos teóricos e epistemológicos condizentes. A concepção de violência adotada neste artigo coaduna-se com a defendida por Ristum e Bastos, ou seja, como um fenômeno socialmente construído e que só pode ser compreendido a partir de uma aproximação das realidades sociohistóricas e culturais nas quais os atores sociais estabelecem relações dialéticas. Perspectiva semelhante é adotada por Guareschi, Weber, Comunello e Nardini (2006), que, ao buscarem compreender a produção de sentidos acerca da violência, afirmam não ser "possível considerar a violência como algo que se esgota no campo individual. Propomos, portanto, entendê-la como práticas complexas, constituídas por diversos vetores, socialmente produzidos" (p. 2).

Nessa mesma direção, observa-se que a produção mais recente da literatura sobre violência tem colocado o que parece estar se tornando um consenso: a impossibilidade de se compreender o fenômeno da violência fora do âmbito das relações sociais. Seja qual for a faceta da violência que os estudiosos focalizam, ela deve ser concreta e historicamente contextualizada.
A violência pode ser considerada um fenômeno que se apresenta por vias objetivas e subjetivas (Porto, 2006). A primeira estaria ligada às estatísticas, que comprovam tanto a existência quanto o crescimento dos atos de violência na sociedade contemporânea. Essa seria uma importante via de acesso ao fenômeno, como argumenta Zaluar, Noronha e Albuquerque (1994), referindose aos dados estatísticos como capazes de fornecer uma contribuição considerável para a compreensão da violência e também de contribuir para derrubar alguns mitos correntes, como aqueles que articulam violência e pobreza ou violência e migração, além de propiciar uma visão abrangente da ocorrência desse fenômeno em todo o território brasileiro de forma atualizada.

Entretanto, Njaine, Souza, Minayo e Assis (1997), ao promoverem uma discussão acerca da circulação das informações sobre a violência no Brasil, chamam a atenção para os pontos cegos que não aparecem nos dados estatísticos, principalmente porque algumas formas de violência não são reconhecidas pela sociedade, permanecendo em uma zona de invisibilidade. Cabe aqui sinalizar, mais uma vez, a importância de se procurar apreender o fenômeno dentro do seu contexto, não se atendo apenas à forma como se apresenta, mas buscando a interpretação daquilo que é tido ou não como um ato de violência para os sujeitos que a estão vivenciando.

É nesse sentido que emerge a segunda via de acesso à violência (Porto, 2006). Esta seria a necessidade de considerar "igualmente o que diferentes indivíduos e sociedades reputam (representam) como violência. Essa representação poderia, em última instância, interferir na própria realidade da violência, reforçando a necessidade de uma estratégia de análise que interrogue sobre as 
Para Teixeira e Porto (1998), "tal como na sociedade, na escola, as situações potencialmente geradoras de violência são permanentes, e não apenas conjunturais"

(p. 60). relações objetividade/subjetividade enquanto componentes que participam da definição do fenômeno da violência e que interferem nas práticas e nas representações que diferentes grupos elaboram de tais práticas" (p. 15).

Em um importante artigo a respeito da trajetória dos estudos sobre violência escolar na França, Debarbieux (2001) conclui que é enganoso supor que a definição permita maior aproximação e apreensão do fenômeno, e propõe que a violência seja estudada a partir de como ela é percebida pelos atores sociais que a vivenciam, em contextos diferenciados.

Aqui as reflexões se voltam para a manifestação do fenômeno da violência no contexto escolar. Dentro das discussões mais amplas do tema, essa vem tendo um destaque considerável nas produções acadêmicas e nos debates travados no cenário público (Lopes \& Gasparin, 2003). Esses autores identificam o final da década de 1980 e o início dos anos 90 como um período marcado pela explosão do debate sobre a violência nas escolas.

Um aspecto a ser ressaltado é que, apesar de estar circunscrito a um âmbito específico, o contexto escolar, o fenômeno não se apresenta menos complexo. Para Teixeira e Porto (1998), "tal como na sociedade, na escola, as situações potencialmente geradoras de violência são permanentes, e não apenas conjunturais" (p. 60). Além disso, as ações ou comportamentos colocados sob esse rótulo são os mais diversos, e isso merece uma reflexão mais aprofundada.

Segundo Charlot (2002), o conceito de violência escolar pode ser classificado em três níveis: o da violência propriamente dita, o das incivilidades e o da violência simbólica ou institucional. Sob o primeiro rótulo, estariam os atos de violência facilmente identificados pelo senso comum como golpes, ferimentos, violência sexual, roubos, crimes, vandalismo, etc. Sob o segundo, estariam as humilhações, as palavras grosseiras, a falta de respeito etc. Já no terceiro estariam as práticas que nem sempre são avaliadas pelos atores como manifestações de violência, possivelmente por estarem arraigadas no cotidiano das escolas, como, por exemplo, a violência que se estabelece nas relações de poder em sala de aula ou a minimização da importância do professor no contexto escolar.

É necessário observar que a classificação acima corresponde apenas a uma das possíveis e existentes na literatura pertinente, e é aqui citada como uma ilustração da complexidade do fenômeno que se propõe estudar.

Outra questão relacionada à delimitação da violência diz respeito à dificuldade de diferenciação entre violência e indisciplina. Camacho (2001), ao apresentar sua pesquisa acerca da violência entre escolares, relata que a fronteira entre a violência e a indisciplina se faz tênue e frágil, de forma que as práticas de indisciplina são "constantemente citadas, e mesmo confundidas, com condutas de violência pelos sujeitos e protagonistas" (p. 6).

Negrão e Guimarães (2006) também destacam a necessidade de um estudo reflexivo acerca da violência e da indisciplina de forma simultânea, "pois ambos os conceitos parecem estar entrelaçados, segundo a percepção de grande parte dos educadores. E mesmo na literatura especializada, há divergências quanto à conceituação e diferenciação dos termos" (p. 2).

Frente a esse cenário de múltiplas possibilidades de manifestações e leituras da 
violência escolar, um outro aspecto emerge como relevante - a compreensão das relações estabelecidas entre os atores que compõem o cenário. As manifestações de violência na escola têm sido estudadas em termos da violência entre alunos, entre alunos e professores ou dirigidas ao patrimônio, para citar as mais comuns.

Lopes e Gasparin (2003), ao abordarem a violência que se manifesta na relação professor-aluno, afirmam que "a presença mais intensa da violência no cotidiano da escola tem aumentado a complexidade da relação professor-aluno e tornado mais agudos os conflitos próprios da relação" (p. 296). Afirmam, mais adiante, que os recursos tradicionais de solução de conflitos utilizados pelos professores, em sala de aula, já não dariam mais conta de resolver as questões que se colocam atualmente, uma vez que estas constituem formas incrementadas de ações violentas.

Para o objetivo do estudo aqui relatado, enfocaram-se as manifestações de violência dirigidas aos professores em sala de aula, pelos alunos de escolas circunscritas em unidades destinadas ao cumprimento de medidas socioeducativas de privação de liberdade.

Se o fenômeno da violência escolar, como colocado anteriormente, carrega em si tantas especificidades e nuances, sua ocorrência no âmbito das escolas para adolescentes autores de infrações tem acrescidas as condições de privação de liberdade, a relação alunoprofessor fiscalizada por um efetivo de segurança e a obrigatoriedade da presença do adolescente na escola como forma de avaliação enviada ao Judiciário, dentre outras. Ao buscar compreender o funcionamento da escola dentro da FEBEM-SP, Lopes
(2006) lança um questionamento acerca da viabilidade de uma escola regular cumprir seus objetivos dentro de uma prisão, contexto que "funciona no registro da contenção, e não no da educação, tendo a escola (professores e direção) pouca autonomia na realização de seu trabalho" (p.13).

O aumento do número de adolescentes que praticam atos infracionais tem levado tanto a sociedade quanto a Academia a se debruçar sobre formas de compreensão dessa prática. Tem-se buscado analisá-las a partir de diferentes construções teóricas, discutindo distintas atuações profissionais como possibilidade de construção de medidas de prevenção e controle de atos delituosos.

O crescimento da violência praticada por jovens demanda que a sociedade lance mão de dispositivos que regulem as medidas a serem aplicadas aos mesmos. Nesse contexto, o Estatuto da Criança e do Adolescente ([ECA] Brasil, 1990) é forjado tanto como regulador de medidas de proteção quanto de sansão. No Estatuto, o adolescente autor de ato infracional é aquele que apresenta "conduta descrita como crime ou contravenção penal" (art.103). Considerando que tal situação de conflito com a lei seja perpassada por aspectos tanto do desenvolvimento do infrator quanto socioculturais e situacionais, o ECA propõe, então, a aplicação de medidas socioeducativas para esses adolescentes.

A autoridade competente, conforme o art. no 112 do ECA, deve aplicar medidas socioeducativas (não privativas ou privativas de liberdade) que objetivam a compreensão dos mesmos quanto à infração e um redirecionamento de seus projetos e opções de vida. Isso acaba por conferir a essas medidas um caráter social e educativo. Além disso, tais medidas possuem níveis 
diferenciados, levando "em conta a sua capacidade de cumpri-la, as circunstâncias e a gravidade da infração" (§ 1).

No âmbito do presente trabalho, dentre essas medidas previstas pelo ECA, interessanos a medida socioeducativa de internação, aplicada nos casos aos quais é atribuída maior gravidade, assim escrita no estatuto: "A internação constitui medida privativa de liberdade, sujeita aos princípios de brevidade, excepcionalidade e respeito à condição peculiar de pessoa em desenvolvimento" (art. 121).

A brevidade se pauta no fato de que não existirão penas perpétuas, sendo que "em nenhuma hipótese o período máximo de internação excederá a três anos" (art. 121, $\S 3)$. A excepcionalidade está relacionada ao fato de que a privação de liberdade não deve constituir fim em si mesma, devendo ser aplicadas outras medidas socioeducativas, se possível, e, por fim, o respeito refere-se à preservação da integridade física e mental dos adolescentes internos.

Durante o período de internação, que vai de seis meses a três anos, o Estatuto determina a obrigatoriedade na participação de atividades pedagógicas (art. 123, parágrafo único). Dentre os direitos assegurados ao adolescente privado de liberdade (art.124), está o de receber escolarização e profissionalização. Para assegurar esse direito, existem, no espaço físico das unidades de internação, instituições escolares municipais e estaduais que propiciam, ao adolescente, início e/ou continuidade do ensino formal.

Percebe-se aí um importante elemento para análises posteriores, que é o duplo status da escola oferecida aos adolescentes que estão cumprindo medida de internação: a escola como direito e como dever. Para vislumbrar essa dupla característica em todo o seu aspecto crítico, é necessário atentar para o fato de que a escola, na maioria dos casos, não é uma realidade presente na vivência dos adolescentes antes do encaminhamento para cumprimento da sentença designada pelo juiz; logo, para alguns dos adolescentes, o contato mais intenso com as práticas escolares se dá nesse momento adverso que constitui a privação de liberdade. Além disso, como já foi ressaltado, a condição em que se encontram os alunos - cumprimento de medida de privação de liberdade, pela prática de atos infracionais - implica uma rotina cercada de especificidades, na qual as práticas educativas e os procedimentos de segurança coexistem no espaço da sala de aula. Tal fato conduz a questionamentos a respeito de como se dá, nesse contexto, a relação professor-aluno. Pode-se encontrar, na literatura, alguns estudos sobre violência escolar que trazem reflexões acerca das relações de conflito entre professores e alunos. Segundo Sposito (2001), estas "têm afetado o clima dos estabelecimentos escolares, especialmente a ação dos professores, que passam a sentirse sob ameaça permanente, quer real, quer imaginária" (p.17). Isso acarreta consequências tanto para a dinâmica relacional quanto para o processo de atuação profissional do docente.

A partir de um levantamento que utilizou como espaço de busca o banco de periódicos da Scientific Electronic Library Online (SciELO), pôde-se constatar a inexistência de artigos brasileiros que relatam pesquisas empíricas abordando a violência escolar nas unidades de cumprimento de medida socioeducativa de internação. Esse contexto é de grande importância para o processo de elaboração de novos projetos de vida para o adolescente que cumpre tal medida e que, ao mesmo tempo, é perpassado por um cotidiano de violências. 
O que essa inexistência de relatos de pesquisas nos periódicos brasileiros parece demonstrar é que o contexto de privação de liberdade não emergiu, ainda, como campo significativo para as pesquisas voltadas para a violência escolar, apesar de ser forjado a partir de um discurso de lastro pedagógicoeducacional, legitimado pelo ECA e pelos dispositivos legais que o executam.

Nesse sentido, as escolas estaduais e municipais, que funcionam dentro das unidades de internação, estariam não apenas comprometidas com a escolarização dos adolescentes mas também com o processo educativo voltado para o cumprimento da medida socio-educativa. Assim, faz-se necessário propor estudos que contribuam para a produção de conhecimento sobre o assunto, através da percepção que os docentes possuem como receptores de ações concebidas como violentas por parte dos alunos.

O objetivo do presente trabalho foi verificar se, na percepção dos professores de uma escola inserida no sistema socioeducativo de privação de liberdade,

A) Os alunos praticam violência contra os professores;

B) Quais são as formas que essa violência assume e

C) Como essas ações consideradas violentas se relacionam com as características de um contexto em que as práticas educacionais ocorrem lado a lado com ações restritivas e punitivas e cercadas por medidas de segurança.

\section{A unidade de atendimento socioeducativo}

Na unidade em que foi realizada a pesquisa, em 2007, havia 230 adolescentes internados, de ambos os sexos, com expressiva predominância do sexo masculino (219 adolescentes).

A rotina pedagógica desses adolescentes se subdivide em dois momentos - a presença na sala de aula e a presença em atividades outras de cunho educativo e esportivo, como jogos e oficinas, nas quais desenvolvem atividades como confecção de artefatos de cimento, panificação, pintura e costura.

Na unidade, funcionam duas escolas, uma estadual e outra municipal. Na escola municipal que é enfocada nesta pesquisa, havia 180 adolescentes, matriculados em doze turmas, nos turnos matutino e vespertino, e oito professores atuando em salas de aula. São elencadas, a seguir, as especificidades que diferenciam a escola no âmbito da unidade de internação das demais escolas da rede municipal de ensino.

Existe um efetivo de funcionários destinados a assegurar a integridade física de professores e alunos em sala de aula, que permanecem, durante todo o período da aula, em frente à porta da sala; a interrupção ou suspensão das aulas pode ocorrer em casos de necessidade de procedimentos no interior da unidade, como, por exemplo, revistas em alojamentos; nos casos de recusa em ser encaminhado para a sala de aula, o aluno se torna alvo de uma série de intervenções, que variam desde sanções até intervenções técnicas; os acontecimentos em sala de aula que são julgados como perturbadores da ordem ou como ameaças aos colegas e/ou professores são encaminhados às coordenações sob forma de relatórios diários; as avaliações dos professores acerca do desempenho do aluno, em sala de aula, integram o corpo dos relatórios de avaliação que são encaminhados ao juiz que acompanha a 
medida socioeducativa aplicada; há um cuidado na formação das turmas para que, nestas, não sejam inseridos adolescentes que possuem conflitos entre si, anteriores à internação ou desenvolvidos dentro da própria unidade.

Observou-se que o número de alunos em sala de aula sofre variação devido a uma série de procedimentos que se colocam no cotidiano da unidade, como, por exemplo, saídas médicas, saídas para audiências e atendimentos psicossociais, dentre outros. Não há um número pré-estabelecido de alunos em sala de aula, mas há o cuidado em formar turmas pequenas, de forma a possibilitar a efetividade das medidas de segurança.

Essas diferenças, aliadas ao estado de privação de liberdade no qual os adolescentes se encontram, constituem elementos que conferem a esse contexto um caráter singular e de grande relevância para a compreensão de fenômenos que circundam a relação ensinoaprendizagem. Essa relação é marcada, ainda, pela participação de docentes que, muitas vezes, não se identificam com a proposta pedagógica das instituições de privação de liberdade, que se sentem inseguros no ambiente da sala de aula e que são forçados a trabalhar com a descontinuidade no processo, por decorrência das características das instituições e de seus alunos.

\section{Método \\ Participantes}

No período em que a pesquisa foi realizada, a escola municipal de ensino fundamental contava com oito professores atuando em sala de aula. Todos foram solicitados a anuir à participação na pesquisa. Os quatro professores que concordaram apresentavam as idades de 39, 42, 45 e 52 anos, sendo um do sexo masculino e três do feminino. Todos possuíam nível superior, e um deles possuía especialização em psicopedagogia. Três dos professores atuavam na unidade com carga horária de 20 horas semanais e um, com 40 horas; apenas um atuava também em outra instituição de ensino.

O tempo de atuação na unidade variou de cinco meses a quatro anos, e o tempo total de exercício do magistério variou de 1 a 30 anos. Todos foram designados para trabalhar na unidade, sem possibilidade de escolha de sua parte.

\section{Instrumento}

Utilizou-se, para a coleta de dados, um questionário composto de duas partes. A primeira parte era estruturada e focalizava dados pessoais e profissionais, caracterizando o participante por sexo, escolaridade, idade, formação, tempo de profissão, tempo de atuação na unidade, carga horária na unidade e atuação em outra instituição de ensino.

A segunda parte, semiestruturada, continha cinco questões abertas. Na primeira delas, utilizou-se a técnica de evocação livre de palavras, sendo solicitado ao participante que escrevesse palavras, frases ou sentimentos que se associavam ao tema violência escolar. Em seguida, foram elaboradas questões sobre: as manifestações consideradas mais relevantes no ambiente da sala de aula na referida instituição, manifestações de violência mais relevantes dirigidas ao professor, exemplos de possíveis manifestações de violência sofridas pelo participante em sala de aula e principais consequências na atuação do professor que é vítima de violência por parte do aluno. Como se pode observar, a formulação dessas questões foi orientada pelos objetivos da 
pesquisa, de forma a compor um instrumento adequado à produção dos dados necessários ao cumprimento dos objetivos propostos.

Procedimentos

Em um primeiro momento, foi realizado um contato com a coordenação da escola e apresentada a proposta da pesquisa. A seguir, houve um encontro da pesquisadora com cada professor, no qual era feito o convite para sua participação na pesquisa. Esses contatos foram realizados no ambiente da escola, tanto no turno matutino quanto no vespertino. Após a aceitação por parte de quatro professores, apresentou-se o Termo de Consentimento Informado para ser assinado, no qual se garante sigilo absoluto sobre a identidade do professor. Posteriormente, foram entregues aos professores os questionários para que fossem respondidos e devolvidos à pesquisadora no dia seguinte.

\section{Resultados e discussão}

As respostas dadas pelos professores foram organizadas em quatro blocos temáticos: expressões associadas à idéia de violência escolar, formas de manifestação da violência em sala de aula, experiências de violência vivenciadas pelos professores e relação que estabeleciam entre violência e sua atuação em sala de aula. Tais blocos foram formados com base nos quesitos do questionário e, portanto, nos próprios objetivos da pesquisa.

Expressões relacionadas à

"violência escolar"

Para os professores, o termo violência escolar remete a falta de educação doméstica, falta de moral e ética, angústia, pânico, medo, família, adolescentes, desemprego, problemas sociais e recursos comunitários insuficientes.
Esses termos citados pelos participantes e transcritos acima se relacionam à maneira como o fenômeno da violência escolar é percebido por estes. Em uma categoria, encontram-se os termos falta de educação doméstica, falta de moral e ética, família, adolescentes, que remetem à violência como produto da falta de uma educação que é ideal, oriunda da família, e à ausência de valores morais e éticos. A falta é, portanto, colocada no aluno. É ele quem não possui aquilo que seria necessário para uma conduta disciplinada em sala de aula.

A outra categoria, composta dos termos angústia, pânico e medo, remete ao que é sentido pelos professores. Tais sentimentos, evocados pela expressão violência escolar, podem ser indicativos de que o fenômeno também leva em conta as consequências psicológicas para aqueles que the estão submetidos. Entretanto, cabe ressaltar que esses termos apareceram nas respostas dos professores com menor tempo de docência. Isso pode levar, também, à suposição de que tais sentimentos se vinculam às incertezas e expectativas acerca de sua prática profissional, de forma que a inexperiência profissional atua como fator agravante dos sentimentos considerados negativos pelos próprios professores.

A presença de termos como desemprego, problemas sociais e recursos comunitários insuficientes diz respeito a questões de cunho social, e indica que a violência escolar pode ser definida em termos do que os professores consideram como causas da violência. Essa relação entre violência e fatores sociais é abordada em alguns trabalhos que se propõem a discutir a violência como fenômeno que possui causas macroestruturais. 
Frente à grande variedade de causas da violência e à falta de consenso sobre elas, Ristum (2006) sugere uma classificação das causas "em função de como o ambiente em que elas se encontram estão relacionados aos que praticam a violência" (p. 32). A classificação proposta se dá em termos de duas categorias: contextuais e pessoais, sendo que a categoria contextual se subdividiria em distais e proximais. As distais seriam aquelas engendradas em contexto social mais amplo, enquanto as proximais estariam nos contextos com os quais os indivíduos possuem contato direto. Assim, as causas relacionadas com questões como as levantadas pelos professores estariam classificadas como contextuais distais. Entretanto, sem minimizar a importância do contexto macrossocial, deve-se atentar para os fatores proximais, especialmente aqueles que estão presentes nas relações que se desenvolvem no âmbito da própria instituição caso se queira evitar, nos termos utilizados por Aquino (1998), uma visão sociologizante, que isenta a escola de qualquer responsabilidade na produção da violência escolar. Ao se referir apenas ao ambiente macroestrutural, as professoras mostram conceber as relações institucionais desvinculadas da violência que se processa na instituição.

\section{A violência na sala de aula}

Acerca das formas de violência no ambiente da sala de aula arroladas pelos professores, emergiram duas principais categorias: uma de violência implícita e a outra, explícita. $\mathrm{Na}$ categoria de violência implícita, as formas de manifestação da violência foram assim colocadas: olhares, expressão facial, gestos dirigidos aos colegas, carência de afeto. Já na explícita, foram citadas palavras, repressões e disputa de poder. Um dos participantes relatou ausência de violência em sala de aula, e explicou essa ausência pelo fato de a escola se localizar em uma unidade de privação de liberdade.

Quando foram solicitados a indicar as manifestações de violência mais relevantes dirigidas aos professores, os participantes também citaram as expressões faciais, palavras intimidadoras, olhares. Foram ainda acrescentadas: cobrança de concentração na sala de aula e cobrança de determinados valores, por parte da instituição, o que indica que o professor percebe as exigências relacionadas à sua atuação como formas de violência. É interessante notar que o mesmo participante que citou ausência de violência em sala de aula também relatou não existir violência dirigida ao professor na sala de aula.

Um primeiro ponto que se faz necessário destacar aqui é essa aproximação, trazida pelos professores, entre as formas de violência típicas do contexto da sala de aula na qual atuam e a violência que é dirigida a eles, ou seja, as formas de violência dirigidas por alguns adolescentes aos colegas não se diferenciam das dirigidas aos professores. Essa constatação leva a pensar na possibilidade de um nivelamento, por parte dos adolescentes, das figuras do professor e daquelas dos colegas, indicando que o exercício do papel de professor não the confere autoridade que o diferencie da posição dos alunos.

Um segundo ponto a ser destacado são as formas de violência que se manifestam no cotidiano das salas de aula de uma instituição de privação de liberdade. Uma vez que esta é caracterizada como uma unidade de segurança, na qual há um efetivo de funcionários cujas atuações se dão no plano da prevenção e da contenção das manifestações de violência física, as 
possibilidades se voltam para as expressões e falas que sugerem uma violência contida, mas não ausente das relações estabelecidas em sala de aula.

De acordo com Camacho (2001), há uma variação nas formas e rituais das práticas de violência nas escolas de acordo com o tempo e com as particularidades do contexto escolar e de seus atores. Em pesquisa desenvolvida acerca das formas sutis de violência nas escolas, a autora sugere que a violência que é perpetrada na presença dos professores e/ ou de outros adultos geralmente é disfarçada, havendo uma diferença entre aquelas que ocorrem fora do campo de visão adulto, que tendem a ser mais explícitas. Partindo dos resultados de sua pesquisa, Camacho propõe a existência de duas formas de prática de violência no contexto escolar - uma mascarada/implícita e a outra nãomascarada/explícita.

A autora chama a atenção, ainda, para o fato de que a violência explícita é aquela para a qual se voltam possibilidades de combate, evitação e punição, pois suas consequências são mais visíveis e imediatas. Por outro lado, a implícita geralmente é banalizada, por ser considerada de menor gravidade. Entretanto, os danos dessa forma de violência podem ser permanentes e igualmente negativos para suas vítimas.

Essas duas categorias também aparecem explicitadas, como já colocado anteriormente, nas respostas dos professores que participaram desta pesquisa. Mas, aqui, ambas emergem na presença de adultos, até porque essa é constante na instituição.

Ao analisar os depoimentos de alunos e professores acerca das formas de violência no contexto escolar, Abramovay et al. (2005) verificaram que:

a ameaça é um recurso utilizado para colocar o outro em posição de subordinação, estabelecendo-se uma relação de poder, principalmente pelo medo, insistindo-se no caráter de violência extrema em sua verbalização. O poder exercido pelas ameaças é singular, porque mina vontades, paralisa reações, recorrendo comumente à linguagem que passa a ter vida própria, constitui um poder em si mesmo. (p. 151)

As autoras colocam que, especialmente no ambiente escolar, onde os ameaçados e ameaçadores estão em contato no dia a dia, as ameaças podem ocasionar sentimentos de impotência e medo. As palavras intimidadoras e os olhares relatados pelos professores podem ser caracterizados como elementos de ameaça que repercutem em suas atuações em sala de aula.

A disputa de poder, citada por um dos professores, merece um destaque frente à realidade na qual o empoderamento de adolescentes e/ou grupos pode conferir a estes capacidade de barganha e uma série de vantagens frente aos pares. Assim, a sala de aula, um espaço de encontro entre adolescentes dos diferentes alojamentos, pode constituir um terreno propício para disputas e subjugações, tanto entre os adolescentes quanto em relação ao professsor. Nesse aspecto, essa escola, assim como aquelas que se encontram fora das instituições de privação de liberdade, emerge como possível espaço de transposição dos conflitos que ocorrem nos ambientes externos a ela (Abramovay et al., 2005).

Quanto à afirmação do participante que relatou nunca ter percebido manifestações de violência em sala de aula, levanta-se um questionamento acerca de como a violência é por ele representada. A que tipo de violência ele se refere com essa ausência? Muitos 
estudiosos da temática (Abramovay et al., 2005; Minayo, 1994; Ristum, 2001, dentre outros) discutem a equivalência que é feita entre violência e agressão física. Consideram ser esta uma das formas de violência mais facilmente identificáveis e consideradas pelos atores sociais; entretanto, chamam a atenção para o fato de que a agressão física é apenas uma das formas possíveis de manifestação da violência, podendo esta ser também psicológica, simbólica ou apresentar-se, no caso da violência entre pares, como forma de bullying indireto, dentre outras.

Embora as limitações do instrumento não permitam um aprofundamento dessa questão, a ausência de violência relatada por um dos participantes pode ser um indicativo de que outras possíveis formas de violência, além da física, não estejam sendo consideradas. Para Negrão e Guimarães (2006), "a maioria não percebe a existência de violência na escola, deixando transparecer que essa evidência se associa, basicamente, a danos físicos" (p. 413).

Acresce-se a essa questão, referente à própria concepção de violência do professor, o fato de que pensar que um contexto que se configura a partir da lógica da segurança possa incluir atos de violência explícita em sala de aula é assumir a fragilidade de um dos pilares que sustentam as unidades de internação.

\section{As experiências de violência}

Quando questionados se já haviam sido vítimas de violência em sala de aula, dois professores responderam negativamente. Os outros dois que responderam positivamente situaram, como acontecimentos mais significativos, a indisciplina na sala de aula, o uso de palavras e gestos que simbolizavam armas de fogo e palavras sutis com o intuito de aterrorizar. Aparecem, mais uma vez, formas implícitas e explícitas que se revelam ameaçadoras aos professores, sendo que nenhuma delas configura violência física.

Pôde-se perceber, durante a atuação como psicóloga de uma das pesquisadoras na referida unidade de internação, e a partir de observações assistemáticas dos adolescentes privados de liberdade nos diferentes espaços pelos quais circulavam na instituição, que estes utilizam mecanismos de intimidação com base nos atos infracionais cometidos e em um suposto caráter de periculosidade que Ihes é atribuído. Os adolescentes costumam lidar, tanto com os colegas quanto com os profissionais que atuam junto a eles, de modo a intimidá-los e, assim, delimitar o espaço de contatos interpessoais e prescrever regras de conduta para os mesmos, como, por exemplo, dar ordens para que não exerçam determinada atividade. De acordo com os professores, esses mecanismos também são utilizados nas relações em sala de aula e emergem através de olhares e palavras intimidadoras.

Outro aspecto importante é que, conforme comentado anteriormente, há uma percepção da indisciplina como ato de violência dirigida contra a figura do professor. Violência e indisciplina na sala de aula são separadas por uma fronteira pouco demarcada, que pode gerar equívocos na análise desses dois fenômenos complexos e multideterminados que atravessam o cotidiano das práticas de ensino. Ao discutir a indisciplina escolar, Aquino (1998) nos convida a indagar sobre as circunstâncias em que ela ocorre, em vez de simplesmente aderir aos discursos que a colocam como um problema que é de responsabilidade exclusiva do aluno.

De acordo com Negrão e Guimarães (2006), "a disciplinarização parece exercer papel crucial, sendo uma espécie de termômetro" 
(p. 410); os alunos devem, então, representar o papel do bom aluno, que implica um ajuste incondicional a normas e regras, muitas das quais esse aluno desconhece ou em cuja elaboração não teve qualquer participação. Há uma necessidade de a escola e as modalidades de ensino nela engendradas regularem tanto a aprendizagem e o rendimento escolar quanto os corpos, tendo sob controle os movimentos físicos e de interação comunicativa dos alunos. Essa concepção é criticada por Aquino (1998) ao argumentar que, para os professores, o bom aluno seria aquele calado e obediente, ranço de um passado histórico no qual a educação escolar se processava nos moldes da repressão e o professor era o operador dessas medidas repressoras em sala de aula.

Cabe aqui acrescentar que os alunos indisciplinados, nesse contexto ao qual a pesquisa remete, são adolescentes que se encontram privados de liberdade e que, em sua grande maioria, apresentam experiências construídas ao largo das noções de disciplina que um contexto formal de ensino exige.

\section{Relação entre violência e atuação dos professores}

Em relação à percepção sobre as principais consequências para a atuação de um professor que é vítima de violência por parte dos alunos, foram citados o medo de continuar lecionando e o desestímulo, possivelmente decorrentes da atuação em um ambiente no qual não se sentem seguros para desenvolver suas atividades. Isso remete à ideia de constante tensão e falta de motivação na atuação docente com adolescentes infratores. Nesse ponto, pode-se retomar a discussão sobre as consequências da violência em forma de ameaças, na prática dos professores.
A insegurança foi a consequência relatada por todos os professores, o que leva à indagação sobre em que medida a presença de funcionários, destinados a assegurar a integridade física tanto dos professores quanto dos alunos em sala de aula, tornase um dispositivo efetivo de proteção no ambiente de trabalho dos professores ou se, ao se colocar de forma acintosa e constante, seria a evidência forte da periculosidade da situação em que atuam os professores.

Um outro aspecto foi ainda indicado pelos professores participantes do estudo de Lopes (2006) sobre os significados que os professores atribuem à escola inserida na FEBEM: a presença de agentes de segurança nas salas de aula "despertava sentimentos ambíguos nos professores" (p. 52). Ao mesmo tempo em que se sentiam mais seguros ao delegar o controle da sala de aula aos agentes, sentiam-se tanto vigiados quanto desautorizados e destituídos de autoridade em seu ambiente de trabalho.

A imagem denegrida (sic) foi a expressão utilizada por um dos professores para relatar a consequência da violência relacionada à preocupação acerca do conceito formulado pelos alunos sobre o professor como figura sem autoridade, incapaz de controlar determinadas condutas dos alunos. Esse tipo de preocupação também se fez presente fora da sala de aula, nas relações entre os adolescentes e outros profissionais da instituição. No caso dos professores, a importância de ter uma imagem de credibilidade junto aos alunos implica conseguir estabelecer uma ordem mínima no funcionamento da sala de aula.

As outras consequências citadas dizem respeito à saúde física e mental dos profissionais. Consequências como depressão e doenças da mente e do corpo emergiram nos relatos de dois participantes. Isso seria um indicativo de que consideram a violência 
no ambiente de trabalho capaz de gerar consequências ligadas à qualidade de vida que transcendem o exercício da prática docente.

Se a atividade docente é referida na literatura como estressante e como fator que afeta a saúde tanto física como mental dos professores (Reis et al., 2006; Carlotto, 2002), supõe-se que essa atividade, ao ser exercida em um ambiente em que os professores se sentem em perigo constante, tenha efeitos bem mais danosos.

Pesquisas voltadas para a compreensão dessas nuances do ambiente de trabalho dos docentes nessas instituições de privação de liberdade trariam, portanto, importantes contribuições para uma compreensão mais ampliada do fenômeno.

\section{Considerações finais}

As discussões presentes neste artigo podem somar-se a tantas outras, produtos de reflexões de pesquisadores acerca do fenômeno da violência escolar. A realidade complexa que é aqui abordada remete à necessidade da realização de novas pesquisas nas escolas destinadas ao ensino de adolescentes em conflito com a lei para que as dinâmicas aí estabelecidas possam ser melhor discutidas e avaliadas.

Pode-se notar que o fato de a escola estar localizada em uma instituição de privação de liberdade e, portanto, de possuir um aparato de segurança e vigilância constantes não implica ausência de manifestações de violência nas salas. Estas se dão principalmente através de gestos, palavras e olhares, não tendo sido referida a violência física dirigida aos professores.

De acordo com os dados obtidos, essas formas de violência que ocorrem no contexto da sala de aula são concebidas pelos professores como elementos capazes de afetar a atuação dos mesmos por serem geradores de insegurança, desestímulo, medo e dificuldades de relacionamento com os alunos. Essa concepção está presente nas respostas dadas até mesmo pelo professor que afirmou não haver ocorrência de manifestações de violência em sala de aula.

Uma questão interessante é que, como revela a literatura sobre a violência na escola, as manifestações dos alunos não podem ser tomadas de forma pontual, deslocadas de seu contexto. Dois pontos são especialmente merecedores de destaque: o primeiro deles refere-se ao fato de que, para alguns dos adolescentes que frequentam a escola em questão, o aprendizado não é uma prioridade, sendo a frequência escolar um bônus para a saída mais rápida da instituição - ir à escola implica uma avaliação positiva frente ao Juiz. O outro fato é que, para esses adolescentes, estar na instituição implica adotar posturas que garantam o respeito entre os pares, o que, muitas vezes, envolve a utilização de formas de violência a fim de demarcar um espaço. Parece que esses dois pontos contribuem para a produção de relações específicas desses adolescentes com a escola e com os professores.

As limitações do instrumento utilizado impossibilitaram o aprofundamento de informações consideradas relevantes para maior compreensão do fenômeno da violência escolar dirigida aos docentes em instituições de privação de liberdade. Algumas questões que dizem respeito, por exemplo, aos conceitos de violência representados pelos professores e o imaginário construído acerca do delito dos alunos parecem constituir pontos cruciais de investigação, uma vez que tais pesquisas possibilitariam traçar um panorama mais adequado dessa realidade onde (in)segurança e educação caminham lado a lado. 


\section{Joelma Oliveira da Silva}

Mestrado em Psicologia. Docente da Faculdade de Tecnologia e Ciências de Feira de Santana, Feira de Santana, BA - Brasil.

\section{Marilena Ristum}

Doutorado em Educação. Docente da Universidade Federal da Bahia, Salvador, BA - Brasil.

E-mail: ristum@ufba.br

\section{Endereço para envio de correspondência:}

Universidade Federal da Bahia, Faculdade de Filosofia e Ciências Humanas, Departamento de Psicologia, Estrada de São Lázaro, 197 Federação - Salvador, BA - Brasil - CEP 40210-730.

E-mail: joelmaoliveira@ibest.com.br

Recebido 5/8/2008, 1ạ Reformulação 5/8/2009, Aprovado 15/8/2009. 


\section{Referências}

Abramovay, M. (Coord.), Valverde, D. O., Barbosa, D. T., Paula, F. P. de, Avancini, M. M. P. et al. (2005). Cotidiano das escolas: entre violências. Brasília, DF: UNESCO, Observatório de Violência, Ministério da Educação.

Aquino, J. G. (1998). A violência escolar e a crise da autoridade docente. Cadernos Cedes, 19(47), 7-19. Recuperado em 20 de junho de 2007, da SciELO (Scientific Electronic Library Online): www.scielo.br

Brasil. (1990, 16 de julho). Lei no 8.069/90, de 13 de julho de 1990. Dispõe sobre o Estatuto da Criança e do Adolescente e dá outras providências. Diário Oficial da União, (Seção I), p. 2.

Charlot, B. (2002). A violência na escola: como os sociólogos franceses abordam essa questão. Sociologias, (8), 432-443. Recuperado em 02 de junho de 2008, da SciELO (Scientific Electronic Library Online): www.scielo.br

Camacho, L. M. Y. (2001). As sutilezas das faces da violência nas práticas escolares de adolescentes. Educação e Pesquisa, 27(1), 123-140. Recuperado em 03 de junho de 2008, da SciELO (Scientific Electronic Library Online): www.scielo.br

Carlotto, M. S. (2002). A síndrome de burnout e o trabalho docente. Psicologia em Estudo, 7(1). 21-29. Recuperado em 03 de junho de 2008, da SciELO (Scientific Electronic Library Online): www.scielo.br

Debarbieux, E. (2001). A violência na escola francesa: 30 anos de construção social do objeto (1967-1997). Educação e Pesquisa, 27(1), 163-193.

Guareschi, N. M. de F., Weber. A., Comunello, L. N., \& Nardini, M. (2006). Discussões sobre violência: trabalhando a produção de sentidos. Psicologia: Reflexão e Crítica, 19(1), 122-130. Recuperado em 20 de outubro de 2007, da SciELO (Scientific Electronic Library Online): www.scielo.br

Lopes, J. S. (2006). A escola na FEBEM - SP: em busca do significado. Dissertação de Mestrado, Instituto de Psicologia, Universidade de São Paulo, São Paulo.

Lopes, C. S., \& Gasparin, J. L. (2003). Violência e conflitos na escola: desafios à prática docente. Psicologia em Estudo, 25(2), 295-304. Recuperado em 22 de agosto de 2007, de www. naoviolencia.org.br/sobre/pdf/Violenciaeconflitosnaescola CLopeseJGasparin.pdf

Minayo, M. C. (1994). A violência social sob a perspectiva da saúde pública. Cadernos de Saúde Pública, 10(supl. 1), 7-18. Recuperado em 03 de junho de 2008, da SciELO (Scientific Electrocnic Library Online): www.scielo.br
Negrão, A. V. G., \& Guimarães, J. L. (2006). A indisciplina e a violência escolar. Núcleos de Ensino/Prograd. Ed. da UNESP. Recuperado em 02 de abril de 2007, de http://www.unesp.br/ prograd/PDFNE2004/artigos/eixo7/aindisciplina.pdf

Njaine, K., Souza, E. R., Minayo, M. C. S., \& Assis, S. G. (1997). A produção da (des) informação sobre violência: análise de uma prática discriminatória. Caderno de Saúde Pública, 13(3), 405-414. Recuperado em 03 de junho de 2008, da SciELO (Scientific Electrocnic Library Online): www.scielo.br

Porto, M. S. G. (2006). Crenças, valores e representações sociais da violência. Sociologias, (16), 250-273. Recuperado em 03 de junho de 2008, da SciELO (Scientific Electrocnic Library Online): www.scielo.br

Reis, E. J. F. B., Araújo, T. M., Carvalho, F. M., Barbalho, L., \& Silva, M. O. (2006). Docência e exaustão emocional. Educação \& Sociedade, 27(94), 229-253. Recuperado em 02 de maio de 2008, da SciELO (Scientific Electrocnic Library Online): www.scielo.br

Ristum, M. (2001). O conceito de violência de professoras do ensino fundamental. Tese de Doutorado, Faculdade de Educação, Universidade Federal da Bahia, Salvador.

Ristum, M. (2006). As causas da violência. Revista GIS. 5. Recuperado em 25 de fevereiro de 2008, de http://www. Itds.ufrj.br/gis

Ristum, M., \& Bastos, A. C. S. (2004). Violência urbana: uma análise dos conceitos de professores do ensino fundamental. Ciência e Saúde Coletiva, 9(1), 225-239. Recuperado em 03 de junho de 2008, da SciELO (Scientific Electrocnic Library Online): www.scielo.br

Sposito, M. P. (2001). Um breve balanço da pesquisa sobre violência escolar no Brasil. Educação e Pesquisa, 27(1), 87-103. Recuperado em 10 de abril de 2007, da SciELO (Scientific Electrocnic Library Online): www.scielo.br

Teixeira, M. C. S., \& Porto, M. R. (1998). Violência, insegurança e imaginário do medo. Cadernos CEDES, 19(47), 51-66. Recuperado em 03 de maio de 2007, da SciELO (Scientific Electrocnic Library Online): www.scielo.br

Zaluar, A., Noronha, J. C., \& Albuquerque, C. (1994). Violência: pobreza ou fraqueza institucional? Caderno de Saúde Pública, 10(supl.1), 213-217. Recuperado em 15 de maio de 2007, da SciELO (Scientific Electrocnic Library Online): www.scielo.br 